\title{
Theorizing the Effect of Smog on Public Health in Lahore, Pakistan
}

\author{
Ali Akbar ${ }^{1}$ \\ ${ }^{1}$ University of Lahore, Pakistan \\ Correspondence: Ali Akbar, University of Lahore, Pakistan. E-mail: AliAkbar.Hameed@outlook.com
}

Received: March 29, 2020

Accepted: July 23, 2020

Online Published: September 28, 2020

doi:10.5539/ep.v9n2p14

URL: https://doi.org/10.5539/ep.v9n2p14

\begin{abstract}
SMOG is a form of horrible air pollution that has recently been declared as a public health emergency in Southeast Asia. This article will talk about the drawback of smog pollution and its outcomes on human health. Smog has become the most important issue for Pakistan, from some past vears. Since 2011, nearly all areas of Pakistan especially Lahore has been repeatedly affected by smog. In Many previous types of research, the focus is on Smog and, its source, alarm systems, and safeguard, when a risky Environmental event like smog, the conclusion may be riskier than the event itself will cause if people take irrational actions due to lack of relevant awareness. So, examine people's attitudes and a reaction to smog is theoretically and realistically meaningful. Recent projects of coal as a source of energy, high rates of outpouring from unmonitored industries, a large number of automobiles on roads, play a maior role in trends of deforestation to construct new roads and recently the burning of crops leftovers has added fuel to the fire. Vehicles increase by $9 \%$ compared to the last five years due to a lack of public transport systems. Pakistan, India, and Bangladesh emit the most hydrocarbons in their fuel emissions compared to SAARC (South Asian Association for Regional Cooperation) countries. As a result of these problems. Pakistan is facing its relatives, losses and various dangerous human diseases.
\end{abstract}

\section{Introduction}

A mixture of smoke and mist plays a leading role to make smog. Exhaust cloud is the Chemical foulness of the air which is the cause of human resources. It is a yellow or black incense fog created by the combination of barometric pollution and ground-level ozone. Exhaust cloud which is now prepared daily can be distinguished as the mixture of gas residues and water vapor. Since clean air is examined one of the most major requirements for a healthy life due to the rise of toxins in the climate. Due to rapid industrialization, we don't have a clean environment to breathe in the smoke traffic. Air pollution is a serious threat to all citizens of the world. Increased levels of pollution and haze can have major effects on the body and psychological health. The rising form of air pollution is smog. According to the Deutsche Welle website, Lahore has been reporting smog for the past few years and is among the tops ten cities affected by smog. Residents of Lahore had received a smog blanket that caused low visibility, shortness of breath and eye diseases, among other problems. During this period, many people were dead due to already suffering from chronic obstructive pulmonary disease (COPD). Every year 1,250 people lose their lives in Lahore due to air pollution because human health and air pollution have strong bonding. The air pollutants responsible for smog are in the form of gases such as carbon monoxide (CO), nitrogen oxide (NOX), ozone (O3), sulfur dioxide (SO2), and volatile organic combination. Solid or Liquid forms are Particulate PM10 (less than 10 $\mu \mathrm{m}$ ) or PM2.5 (not more than $2.5 \mu \mathrm{m}$ ), and a few are air toxins.

Vehicle discharge contributed to the inclusion of carbon monoxide in air pollution. This increase can be minimized by the use of motor vehicle calibration and control (Aziz and Bajwa, 2007)

Especially in the region, many parts of the world have not experienced smog. As reported by Deutsche Welle, The top ten countries included with Lahore, New Delhi is on top of the list and other beings, Riyadh, Mexico City, Ahvaz, Beijing, Cairo, Dhaka, Moscow, and Alan Bauer. (Welle, 2017). In 1952, Greater London suffered a notorious smoke, which allegedly killed 3500 to 4,000 people in a short period. (Authority, 2002).

The release of smoke from factories and vehicles globally in the composition of the smog is contributing to the spread of sewer smog in Los Angeles in the 1950-1960s. (Boffey, 1968). Cars accounted for $62 \%$ of the composition of photochemical smog in Bangkok (Zhang and Oanh, 2002). China suffered violent episodes from early 2013 due to high concentrations of environmentally fine particles. Zhou et al. (2015).

Although there have been recent advances research in the scope of people's perceptions of environmental events, 
recent research on air pollution has primarily focused on the technical knowledge of pathogens and chemical processes, and some studies have responded to smog Treats of people's behavior and behavior. When faced with dangerous environmental events such as smog, the result can be worsening if people commit illogical actions due to a lack of relevant education. (Sun et al. 2016). Both practically and theoretically investigation of air pollution is important by behaviorally and psychologically

Then as well, Lahore is one of the biggest city of Pakistan by population and faces dust or road dust due to the emissions of industrial, construction and gas vehicles. All of them have increased pollution in the environment, especially PM2.5, which is four times higher than summer data recorded from November 2005 to December 2007. In November 2016, Lahore experienced smog for the first time. (Lodhi et al. 2009).

\section{The Composition of the Smog}

Environmental pollution and the gases that cause brown haze is everywhere when coal is burned. Brown mist is created when daylight and its temperature are interconnected with gases and fine particles of air that are due to air pollution. At this time, when the reaction among the unexpected natural mixtures (VOC), nitrogen oxide (NO), and sulfur dioxide (SO2) occurs, the fine particles and ground surface ozone are released into the atmosphere. All of these uncertain natural mixtures, nitrogen oxide, and sulfur dioxide, are the ancient ones whose main constituents in the predators are poison, which is excluded from diesel motors, gas, modern plants and more heat drills. This is often due to high temperatures, appropriate traffic, and more temperature cause or humidity. These are the main reasons behind the brown haze problem. During winter the airspeed decreases as the mist stopped and smoke. In a place that is the primary driver of cloud formation and is excessively destructive to the ordinary population at ground level, that hurts the nature and our local deception. Brown mist depends only on the temperature because the temperature is reversed or the air cannot move upwards and cannot stay on the surface of the earth which acts as a cloud.

\section{Effects of Smog on the Human Body}

Exhaust clouds are unnatural to people, to creatures, to plants that do not stand for the whole of nature, is because they become part of it. Many people were listed as passing through brown mist or suffering from various dangerous diseases. Adequate exhaust cloud superintendents reduce light radiation. Heavvweight exhaust cloud an important component of nutrient $\mathrm{D}$ results in low production is required for the example of the racquet in individuals. Exhaust cloud can cause of the excavator problem can be fatal for dangerous diseases, for example, a variety of lungs malignant growths are expected to increase pneumonia in the eve. That is why we should not go out in the exhaust cloud. It can affect the initial risks of your body, and asthma attacks because people are tolerating the infection. In most affected people there were elderly, child, and cardiovascular and respiratory complaints. Brown haze is as well as the principal reason for the trouble and According to the news reference, many people are losing their lives date 19/1/2018 report There are about 20000 cloud passing parcels in Pakistan. In Figure: 1 


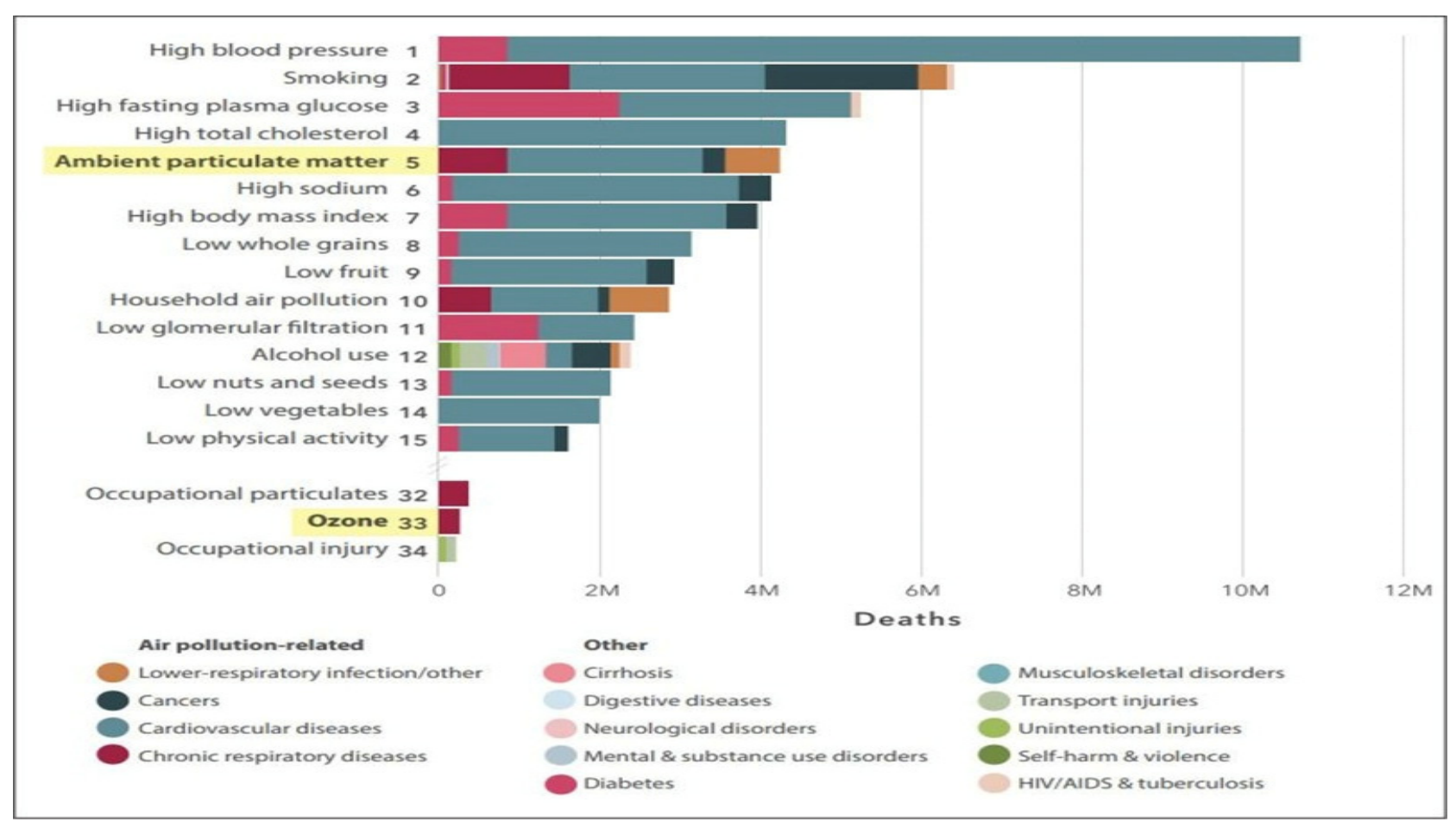

Figure 1. Effects of smog

\section{Reasons behind Why Air Pollution Increase in Pakistan}

Pollution is increasing constantly

Globalization

Urbanization

Usage of heavy transport

High climate or hot weather

Birks fireplace

Lack of planting

Increasing population means increasing needs, and demand of People who cause pollution.

\section{Catastrophe by Smog in Pakistan}

Air specification in Pakistan has over to safe limits in all main cities and, Lahore is 9x poor than national guidelines. (PAQI data).

Every year, 135,000 deaths are associated with air pollution, making it the dominant cause of diseases and deaths in Pakistan, and also reducing expected age by 60 months. Smog is a public health emergency. In Pakistan there is $5.88 \%$ of GDP or $\$ 47.8$ billion is the roughly economic burden of air pollution. The immediate response to air pollution is economically meaningful.

Air pollution is a source of genuine health problems such as respiratory failure, lungs, and heart diseases. 


\begin{tabular}{|c|c|c|c|c|c|c|}
\hline & Index Values & PM 2.5 conc. & Lahore & Peshawar & Islamabad & Karachi \\
\hline Good & 0 to 50 & $0.0-12.0$ & 2 & 1 & $\mathbf{0}$ & 4 \\
\hline Moderate & 51 to 100 & $12.1-35.4$ & 39 & 224 & 57 & 157 \\
\hline Sensitive & 101 to 150 & $35.5-55.4$ & 47 & 48 & 105 & 97 \\
\hline Unhealthy & 151 to 200 & $55.5-150.4$ & 101 & 87 & 143 & 50 \\
\hline Very Unhealthy & 201 to 300 & $150.5-250.4$ & 39 & 5 & 10 & 2 \\
\hline Hazardous & 301 to 500 & $250.5-500$ & 36 & $\mathbf{0}$ & 2 & $\mathbf{0}$ \\
\hline \#nodata & & & 101 & 0 & 48 & 55 \\
\hline \multicolumn{7}{|c|}{$\begin{array}{l}\text { Lahore has the worst air quality in Pakistan, with } \\
\mathbf{2} \text { blue sky days in } 2017 \text { with \#Good air quality, and } \\
\mathbf{3 6} \text { days with \#Hazardous air pollution. } \\
\text { Air Quality index for Health impact as defined by the USA EPA. The Environmental Protection Agency of Pakistan (PKKEPA) } \\
\text { recommended } 15 \mu \mathrm{m} / \mathrm{m}^{2} \text { as the safe level fory early exposure, after which serious health effects occus. The WHO guideline } \\
\text { value is } 10 \mu \mathrm{\mu} / \mathrm{m}^{3} \text { ? }\end{array}$} \\
\hline
\end{tabular}

Figure 2. Pakistan air quality initiative

\section{Diseases can Spread by Smog}

Smog reduced the visionless up to 20-25 meters in Lahore city. This led many people to have acute respiratory illnesses, and eye irritation and infections that were inhabited or were moving to the city, resulting in a controlled patient burdened in hospitals and clinics. The most important signs and manifestations were eyes burning, heavy breathing, and sneezing, wheezing, and a bad cough. Smog is also harmful to the cardiovascular system. There are no safe levels of smog because even the fine ozone particles (even in scars) are dangerous. The ozone layer is found high in the environment, although protected by ultraviolet rays, it acts as pollution at ground level, and its long-term high ground level can permanently damage lung tissue.

\section{Respiratory System}

It takes part a significant role in the human body. The main role of the respiratory system is to transfer oxygen to all parts of the body with blood. The respiratory system does this process by breathing. Breath is taken through the nose, mouth, lungs, and trachea. In the breathing process, we take oxygen and out carbon dioxide. This gas exchange system is the source of oxygen in the blood through the respiration. Therefore, it's proving that the respiratory system plays a vital role in making a person healthful or unhealthy. So if the air gets dirty, we can't suppose a person to be healthy or not. So in these conditions, a human suffers from diseases exceptionally lung cancer and asthma.

\subsection{Asthma}

A long-standing lung disease that burns and tightens the airways, called Asthma. Asthma causes wheezing periods (whistling when you breathe), shortness of breath, chest tightness, and cough. Coughing comes at night or early in the morning. Asthma upset people of all ages, but it starts in childhood. More than 22 million people put up with asthma In the United States, About Six million of them are children. (nhlbi.nih.gov)

\subsection{Lung Cancer}

Lung cancer is the leading cause of cancer-related mortality in men and the second most common in women. Lung cancer killed 1.3 million people worldwide annually. There are two main types of lung cancer: one consisting primarily of small cell lung cancer (SCLC) and the other is an (NSCLC) non-small cell lung cancer. The National Cancer Institute (NCI) in the United States found that 215,020 new cases and 161,840 cancer deaths occurred in 2008. Currently, industrial air pollution is treated to be the leading cause of lung cancer. People who live near the industry areas most worried about industrial air pollution. (rnjournal.com).

\section{Conclusions and Recommendations}

This review presents the adverse impacts of Smog on human health, triggering, numerous ailments leading to high morbidity and moralities, predominantly in the developing countries. Therefore, because of greater exposure to 
diverse pollutants in humans, dietary interventions such as organic foods derived from plants may protect different organs from their effects. Air pollution (Smog) control is the need of the hour and should be on the topmost priority of the governments. The policymakers in developing countries must update all the laws, and regulations associated with air pollution, so that the public can be helped in this regard, as for as possible. A powerful environmental protection organization must be led to coordinate among different departments for combating Smog. An operative environmental protection organization should have enough budgets for administration, monitoring, research, and development to have full control of the environment-related problems including Smog.

\section{References}

Air quality report 2017: Here's how major Pakistani cities get along this year.

Aziz, A., \& Bajwa, I. U. (2007). Minimizing human health effects of urban air pollution through Quantification and control of motor vehicular carbon monoxide (CO) in Lahore. Environmental Monitoring and Assessment, 135, 459-464. https://doi.org/10.1007/s10661-007-9665-7

Dawn. Lahore smog. It's not natural phenomenon. Retrieved from http://www.dawn.com/news/1159190

Deutsche Welle made for minds. (2017). Retrieved from http://www.dw.com/en/top-10-worst-cities-forsmog/g17469135

Great London Authority. (2002). The struggle for air quality in London since the great smog of December 1952. Greater London Authority, London.

How smog can affect allergies and asthma. Retrieved from http://www.webmd.com/allergies/features/smog-notan-allergenbut-an-irritant

http://aqicn.org/?city=Pakistan/Lahore\&size=xlarge\&lang=en\&wamap

http://www.arb.ca.gov/knowzone/students/airpollu/airpolpage/whyis.htm

http://www.arb.ca.gov/knowzone/students/airpollu/airpolpage/whyis.htm

https://tribune.com.pk/story/1626767/1-lahore-smog-clean-air-breathe/

https://www.weatherbug.com/air-quality/lahore-punjab-pk

Is the air we breathe killing us? Dawn News

Lodhi, A., Ghauri, B., Khan, M. R., Rahman, S., \& Shafique, S. (2009). Particulate matter (PM2. 5) concentration and source apportionment in Lahore. Journal of the Brazilian Chemical Society, 20, 1811-1820. https://doi.org/10.1590/S0103-50532009001000007

National environmental quality standards for ambient air.

Sun, C., Yuan, X., \& Xu, M. (2016). The public perceptions and willingness to pay: From the perspective of the smog crisis in China. J. Cleaner Product, 112, 1635-44. https://doi.org/10.1016/j.jclepro.2015.04.121

The air we breathe: is it safe? Retrieved from http://bodyandhealth.canada.com/healthfeature/gethealthfeature/The-Air-WeBreathe-Is-It-Safe

Zhou, M., He, G., Fan, M., Wang, Z., Liu, Y., Ma, J., ... Wang, L. (2015). Smog episodes, fine particulate pollution and mortality in China. Environmental Research, 136, 396-404. https://doi.org/10.1016/j.envres.2014.09.038

\section{Copyrights}

Copyright for this article is retained by the author(s), with first publication rights granted to the journal.

This is an open-access article distributed under the terms and conditions of the Creative Commons Attribution license (http://creativecommons.org/licenses/by/4.0/). 